\title{
Pharmacogenetics of Patients Treated by Biologics - Pilot Study
}

\author{
${ }^{1}$ Vašků A, ${ }^{2}$ Charvátová $H,{ }^{2}$ Slonková V, ${ }^{3}$ Urbanček $S,{ }^{2}$ Vašků V \\ ${ }^{1}$ Department of Pathophysiology, Faculty of Medicine, Masaryk University, Czech Republic \\ ${ }^{2}$ First Department of Dermatovenereology, St. Anne's Faculty Hospital and Faculty of Medicine, Masaryk University Brno, Czech \\ Republic \\ ${ }^{3}$ Department of Dermatology, Slovak Medical University, Banska Bystrica, Slovakia \\ *Corresponding author: Vašků A, Department of Pathophysiology, Faculty of Medicine, Masaryk University, Czech Republic
}

\section{ARTICLE INFO}

Received: 幽 December 15, 2019

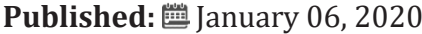

Citation: Vašků A, Charvátová H, Slonková V, Urbanček S, Vašků V. Pharmacogenetics of Patients Treated by Biologics - Pilot Study. Biomed J Sci \& Tech Res 24(2)-2020. BJSTR. MS.ID.004022.

Keywords: Psoriasis; ACE; MMP-2; MMP9; MDR-1; Genetics; Biologics

\section{ABSTRACT}

Introduction: The aim of the study is to evaluate influence of genetic variability in some proinflammatory genes on efficacy of adalimumab therapy in patients of psoriasis and on psoriasis development in patients with other autoimmune diseases treated by different biologics.

Methods: In the study, three patients with biologics were compared: 11 patients with psoriasis with finished treatment with adalimumab (A), 14 patients with psoriasis successfully treated by adalimumab (B), and 12 patients with other diagnosis treated by biologics with development of psoriasis (group C, 1 patient with hidradenitis suppurativa, 4 patients with $\mathrm{m}$. Crohn, 3 patients with ulcerative colitis, 3 cases with ankylosing spondylitis, 1 patient with rheumatoid arthritis). These patients were treated by different biologics. In all patients, several polymorphisms in proinflammatory genes (I/D ACE, MMP-2, MMP-9, and in MDR1) were examined.

Results: Significantly lower effect of adalimumab treatment in 3 months in the A group compared to B group was observed $(\mathrm{P}=0.009)$, more frequently in women. In A group, a significant association of I/D ACE genotype with PASI and BSA before onset of adalimumab treatment and with positive family history of psoriasis at the first-degree relatives (parents, children, siblings) with MMP-9 -1575 T/C genotype. In B group, a longer successful treatment by adalimumab in GG genotype carriers in TNF alpha - 308 $\mathrm{A} / \mathrm{G}(\mathrm{P}=0.03)$, better treatment effect in the TT genotype of MMP-2 $-790 \mathrm{~T} / \mathrm{G}(\mathrm{p}=0.04)$ and in the CC genotype of MMP- $9-1575 \mathrm{~T} / \mathrm{C}(\mathrm{P}=0.04)$ were found. In the heterogeneous $\mathrm{C}$ group, duration of biologics treatment correlated with onset of psoriasis from the beginning of the therapy by biologics and was significantly associated with the MDR1 polymorphism.

Conclusion: Finally, it is possible to conclude that success of biologics therapy is associated with some germ line genotypes in especially proinflammatory genes. Psoriasis development as a consequence of biologics treatment in different autoimmune diseases seems to be related to MDR1 gene variability which can responsible for many pharmacokinetic and pharmacodynamics aspects of therapy.

\section{Introduction}

Autoimmune disease, characterized by the host's immune response against self-antigens, manifests in more than 100 different types and affects more than $10 \%$ of the world's population, causing significant morbidity. Psoriasis is amongst the most common autoimmune diseases affecting approximately $2 \%$ of people globally. The disease is a result of the net outcome of genetic and environmental factors whose multilevel interaction is not fully understood yet. Intense research efforts to date, had focused on examining these factors in isolation, resulting in hundreds of genetic risk loci identified, many of which are shared between the members of the autoimmune disease spectrum, such as psoriatic arthritis, Crohn's disease and others. This genetic overlap seems 
to be an indication of overlap of common causal pathways [1]. The therapies for psoriasis are mainly symptomatic and sometimes with poor response. Response among patients is very variable. This variability may be partly explained by the effect of different genetic backgrounds. On the other hand, clinical manifestation of psoriasis can be developed during biologics therapy in patients with other autoimmunity diseases as a result of shared etiopathogenetic background of these diseases.

Using pharmacodynamics and pharmacokinetics approach, pharmacogenetics and, of course, pharmacogenomics with the whole genome knowledge, is able to describe the inheritance influence on organism response to different drugs as well as on the effect of dose, velocity of starting of effect, on different time of elimination of drug from the body and drug interactions. Necessity of precious diagnosis is of the greatest importance, because different pato biochemical mechanisms can lead to similar phenotypic characteristics of the disease. Individual response on therapy can be modified by gene polymorphisms and/or even rare alleles in those genes which directly or indirectly enter the interactions with effect and/or metabolism of drug [1,2]. Pharmacogenetics and pharmacogenomics are being used also to search for biomarkers that can predict response to systemic treatments, including those for moderate-to-severe psoriasis. Diverse systemic and biologic therapies are used to treat moderateto-severe psoriasis. Moderate-to-severe psoriasis is usually treated with systemic immunomodulators such as acitretin, cyclosporine, and methotrexate.

Anti-tumor necrosis factor (TNF) drugs (adalimumab, etanercept, or infliximab) are the first-line treatment for patients resistant to conventional systemic therapies. Adalimumab was initially approved in 2002 for the treatment of rheumatoid arthritis. It has subsequently been approved for $>10$ additional indications, including moderate to severe plaque psoriasis [3]. Because psoriasis has commonly higher prevalence in many other diseases with autoimmune features, biologics therapy potentially can improve or deteriorate clinical manifestation of psoriasis. This could be individually influenced by gene polymorphisms forming genetic predisposition to chronic inflammatory diseases. Although these therapies are very efficient, around $30-50 \%$ of patients have inadequate response. Ustekinumab is a monoclonal antibody that targets interleukin (IL)-12 and IL-23 and is used for moderate-tosevere psoriasis. New drugs (apremilast, brodalumab, guselkumab, ixekizumab, and secukinumab) have recently been approved for psoriasis. However, response rates to systemic treatments for moderate-to-severe psoriasis range from 35 to $80 \%$, so it is necessary to identify non-invasive biomarkers that could help predict treatment outcomes of these therapies and individualize care for patients with psoriasis. These biomarkers could improve patient quality of life and reduce health costs and potential side effects $[1,2]$. However, very few pharmacogenetic studies have examined the relationship between germline gene polymorphisms and the response to biologicals $[3,4]$. Aim of the pharmacogenetic pilot study was to compare three different groups of patients with biologics treatment in genotype distributions and/ or allelic frequencies of some germline polymorphisms in gene participating on immunomodulation during chronic inflammatory state [5].

\section{Material and Methods}

a) Group A: 11 psoriatic patients treated by adalimumab for three months when the treatment was stopped due to insufficient efficacy of disease (Table 1)

b) Group B: 14 psoriatic patients with efficient continuous therapy by adalimumab (Table 1 )

Table 1: Descriptive parameters for Group A and B.

\begin{tabular}{|c|c|c|c|}
\hline Dg. Psoriasis & $\begin{array}{c}\text { Group A } \\
\text { Adalimumab treatment finished }\end{array}$ & $\begin{array}{c}\text { Group B } \\
\text { Adalimumab treatment continues }\end{array}$ & P \\
\hline Birth year (median, range) & $1953(1928-1991)$ & $1969(1943-1992)$ & NS \\
\hline Sex M/W & $4 / 7$ & $12 / 2$ & $0.02(0 R=10)$ \\
\hline PASI before (median, range) & $14.5(6.3-28.2)$ & $12.9(10.40-40.00)$ & NS \\
\hline BSA before (median, range) & $25(5-60)$ & $25.5(8-75)$ & NS \\
\hline Efficacy of treatment in 3 months & $6 / 5(55 \%)$ & $14 / 0(100 \%)$ & $0.009(0 R=11)$ \\
\hline Psoriasis onset age (median, range, years) & $21.5(0-60)$ & $21.0(7-53)$ & NS \\
\hline Late onset of psoriasis (above 40 years & $20 \%$ & $8 \%$ & NS \\
\hline
\end{tabular}

Table 2: Patients with psoriasis manifestation during biologics therapy.

\begin{tabular}{|c|c|c|c|c|}
\hline Birth year & Sex & Dg & Biologics & $\begin{array}{c}\text { Length of treatment } \\
\text { by biologics } \\
\text { (months) }\end{array}$ \\
\hline 1962 & M & $\begin{array}{c}\text { Clinical manifestation of psoriasis } \\
\text { from the beginning of the } \\
\text { biologics treatment (months) }\end{array}$ & 3 \\
\hline 1985 & suppurativa & adalimumab & 22 \\
\hline 1957 & M & Ankyl spondilitis & adalimumab & 5 \\
\hline 1970 & M & Ankyl. Spondilitis & golimumab & 5 \\
\hline
\end{tabular}




\begin{tabular}{|c|c|c|c|c|c|}
\hline 1962 & W & Iridocyklitis, m.Crohn & adalimumab & 12 & 8 \\
\hline 1976 & W & m. Crohn & adalimumab & 10 & 45 \\
\hline 1976 & W & m.Crohn & infliximab & 42 & 34 \\
\hline 1985 & W & m.Crohn & infliximab & 3 & 2 \\
\hline 1970 & M & Ulcerose collitis & infliximab & 38 & 21 \\
\hline 1952 & W & Ulcerrose collitis & infliximab & 91 & 49 \\
\hline 1976 & W & Ulcerose collitis & infliximab & 66 & 66 \\
\hline
\end{tabular}

c) Group C: 12 patients with other than psoriatic diagnosis (1 case of hidradenitis suppurativa, 4 cases of m. Crohn, 3 cases of ulcerative colitis, 3 cases of ankylosing spondylitis, 1 case of rheumatoid arthritis, Table 2) in which clinical manifestation of psoriasis developed during different biologics therapy. Genotypes in several germline genetic polymorphisms - I/D ACE (rs4646994), TNF alpha -308 G/A (rs1800629), MMP-2 -690 T/G (rs243864) and MDR 1 C3435T (rs1045642) were identified by the PCR method and restriction analysis according to standard protocols.

\section{Results}

A significantly lower 3 months' effect of adalimumab therapy in A compared to B group was confirmed (A group - 6 positive response to 5 negative responses to group B-14 positive to 0 negative; $\mathrm{P}=0.009$; Table 1). In the A group, a significant association of II genotype in I/D ACE polymorphism and higher value of PASI and BSA markers before starting of adalimumab therapy was found $(\mathrm{P}=0.02 ; \mathrm{P}=0.03$, respectively; Table 3 ).A positive family history of psoriasis in the 1 st heredity line (parents, siblings, children), was associated with genotypes in $-1562 \mathrm{C} / \mathrm{T}$ MMP-9 $(\mathrm{P}=0.03$; sensitivity 1 , specificity 0.86 for CT genotype; Table 4) A significant association of duration of biologic treatment with genotypes of TNF- $\alpha-308$ $A / G$ was found $(P=0.03)$. The GA genotype carrier was treated significantly longer (median 35 months, range 17-87 months) compared to genotype GG carrier (median 15, range 2-30 months). The three months ( $3 \mathrm{M}$ ) effects of biological therapy differ between carriers of genotype TG and TT of MMP-2 -790T/G (sensitivity 0.7 and specificity 1 for $\mathrm{TG}, \mathrm{P}=0.04$ ).

Table 3: Differences in genotype distribution in I/D ACE polymorphism in PASI and BSA score before adalimumb therapy onset in Group A.

\begin{tabular}{|c|c|c|c|c|c|c|c|c|c|}
\hline $\begin{array}{c}\text { I/D ACE - } \\
\text { genotypes }\end{array}$ & N & $\begin{array}{c}\text { PASI before } \\
\text { Minimum }\end{array}$ & $\begin{array}{c}\text { PASI before } \\
\text { Maximum }\end{array}$ & $\begin{array}{c}\text { PASI before } \\
\text { Median }\end{array}$ & P & $\begin{array}{c}\text { BSA before } \\
\text { Minimum }\end{array}$ & $\begin{array}{c}\text { BSA before } \\
\text { Maximum }\end{array}$ & $\begin{array}{c}\text { BSA before } \\
\text { Median }\end{array}$ & $\begin{array}{c}\text { P } \\
\text { ID+DD }\end{array}$ \\
\hline II & 3 & 6 & 25 & 9 & 0.02 & 5 & 40 & 16 & 0.03 \\
\hline All Groups & 11 & 23 & 28 & 25 & & 38 & 60 & 50 & \\
\hline
\end{tabular}

Table 4: Differences in genotype distribution in -1562 T/C MMP-9 polymorhisms in family history of psoriasis in Group A.

\begin{tabular}{|c|c|c|c|}
\hline MMP-9 -1562 T/C - genotypes & $\mathbf{N}$ & Parents/siblings/children have not psoriasis & Parents/siblings/children have psoriasis \\
\hline CT & 4 & $1(14 \%)$ & $3(100 \%)$ \\
\hline CC & 6 & $6(86 \%)$ & $0(0 \%)$ \\
\hline All Groups & 10 & 7 & 3 \\
\hline
\end{tabular}

Similarly, the CT genotype carriers in MMP9-1562 C/T from the beginning of the biological therapy until psoriasis became polymorphism have more frequently good response to adalimumab clinically manifest $(\mathrm{P}=0.00002)$. Duration of biological treatment therapy in 3M period compared to TT genotype carriers (sensitivity was also significantly associated with C3435T MDR1 genotype 0.6, specificity 1.0; $\mathrm{P}=0.07$; Table 5) In the $\mathrm{C}$ group, duration of $\quad(\mathrm{P}=0.02$, Table 6). biological therapy highly significantly correlated with the time

Table 5: Differences in genotype distribution in -790 T/G MMP-2 and -1562 T/C MMP-9 polymorhisms in family history of psoriasis in Group B.

\begin{tabular}{|c|c|c|c|}
\hline -790 T/G MMP-2- genotypes & N & 3M efficacy of adalimumab - good & 3M efficacy of adalimumab - bad \\
\hline TT & 7 & $3(30 \%)$ & $4(100 \%)$ \\
\hline TG & 7 & $7(70 \%)$ & $0(0 \%)$ \\
\hline -1562 T/C MMP-9- genotypes & 6 & & \\
\hline CT & 8 & $6(60 \%)$ & $0(0 \%)$ \\
\hline CC & $4(40 \%)$ & $4(4 \%)$ \\
\hline
\end{tabular}


Table 6: Differences in genotype distribution in -790 T/G MMP-2 and -1562 T/C MMP-9 polymorhisms in family history of psoriasis in Group B.

\begin{tabular}{|c|c|c|c|c|}
\hline MDR1-C3435T-genotypes & $\begin{array}{c}\text { Duration of biologics } \\
\text { treatment N }\end{array}$ & $\begin{array}{c}\text { Duration of biologics } \\
\text { treatment minimum } \\
\text { (months) }\end{array}$ & $\begin{array}{c}\text { Duration of biologics } \\
\text { treatment maximum } \\
\text { (months) }\end{array}$ & $\begin{array}{c}\text { Duration of biologics } \\
\text { treatment Median } \\
\text { (months) }\end{array}$ \\
\hline TT & 4 & 3 & 38 \\
\hline CT & 7 & 5 & 66 \\
\hline CC & 1 & 91 & 91 \\
\hline All Groups & 12 & 3 & 91 \\
\hline
\end{tabular}

\section{Discussion}

Drug survival of biologics represents their real-world effectiveness and safety. When a meta-analysis of real-world evidence on the drug survival of biologics in treating psoriasis had been performed, 37 studies with 32,631 subjects were included. The drug survival for all biologics decreased with time, dropping from $66 \%$ at year 1 to $41 \%$ at year 4 for etanercept, from $69 \%$ to $47 \%$ for adalimumab, from $61 \%$ to $42 \%$ for infliximab, and from $82 \%$ to $56 \%$ for ustekinumab [6]. Certainly, individual genome variability must be to some extent responsible for these results. But, so far, pharmacogenetic studies in psoriasis have generated divergent results. Replication of findings in larger cohorts is required [7] Our pilot study tries to accent the importance of knowledge of interindividual variability in the main inflammatory genes which can substantially influence all pharmacological aspects of systemic therapy of psoriasis. According to our results, an association of duration of biologic treatment with genotypes of TNF- $\alpha-308$ A/G was found. Patients with another polymorphic TNF- $\alpha-238$ GG genotype treated by biologics more frequently achieved a PASI75 at 6 months and those with the TNF- $\alpha$-857CT/TT genotypes showed greater improvements in PASI score and BSA and more frequently achieved PASI75 in the study of Gallo et all. [5]

Several studies evaluated changing levels of TNF- $\alpha$ and MMP-9 in tissue and/or serum of psoriasis patients treated with biologics but without genetic variability of susceptible genes [6,7]. We can conclude that efficacy of biological treatment is associated with some germ cell (innate) genotypes in genes contributing to inflammation and wound healing (TNF alpha, matrix metalloproteinases). Besides duration of treatment, clinical manifestation of psoriasis in patients with other autoimmune diagnosis treated by biologics seems to be associated with genotype in MDR-1 gene. Our pilot results support necessity of evaluation of interindividual genome variability in clinical studies which can support further introducing of personalized medicine during development of new drugs for (not only) psoriasis treatment $[8,9]$.

\section{References}

1. Vasilopoulos Y (2017) Pharmacogenetics and psoriasis: is targeted treatment a possibility? Pharmacogenomics 18(18): 1627-1630.

2. Ovejero Benito MC, Muñoz Aceituno E, Reolid A, Saiz Rodríguez M, Abad Santos F, et al. (2018) Pharmacogenetics and Pharmacogenomics in Moderate-to-Severe Psoriasis. Am J Clin Dermatol 19(2): 209-222.

3. Strober B, Crowley J, Langley RG, Gordon K, Menter A, et al. (2018) Systematic review of the real-world evidence of adalimumab safety in psoriasis registries. J Eur Acad Dermatol Venereol 32(12): 2126-2133.

4. Linares Pineda TM, Cañadas Garre M, Sánchez Pozo A, Calleja Hernández MÁ (2016) Gene polymorphisms as predictors of response to biological therapies in psoriasis patients. Pharmacol Res 113(A): 71-80.

5. Gallo E, Cabaleiro T, Román M, Solano López G, Abad Santos F, et al. (2013) The relationship between tumour necrosis factor (TNF)- $\alpha$ promoter and IL12B/IL-23R genes polymorphisms and the efficacy of anti-TNF- $\alpha$ therapy in psoriasis: a case-control study.Br J Dermatol. 169(4): 819-829.

6. Lin PT, Wang SH, Chi CC (2018) Drug survival of biologics in treating psoriasis: a meta-analysis of real-world evidence. Sci Rep 8(1): 16068.

7. van Vugt LJ, van den Reek JMPA, Coenen MJH, de Jong EMGJ (2018) A systematic review of pharmacogenetic studies on the response to biologics in patients with psoriasis. Br J Dermatol 178(1): 86-94.

8. Mastroianni A, Minutilli E, Mussi A, Bordignon V, Trento E, et al. (2005) Cytokine profiles during infliximab monotherapy in psoriatic arthritis. Br J Dermatol 153(3): 531-536.

9. Cordiali Fei P, Trento E, D Agosto G, Bordignon V, Mussi A, et al. (2006) Decreased levels of metalloproteinase- 9 and angiogenic factors in skin lesions of patients with psoriatic arthritis after therapy with anti-TNFalpha. J Autoimmune Dis 3: 5 .
ISSN: 2574-1241

DOI: $10.26717 /$ BJSTR.2020.24.004022

Vašků A. Biomed J Sci \& Tech Res

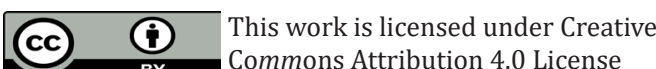

Submission Link: https://biomedres.us/submit-manuscript.php

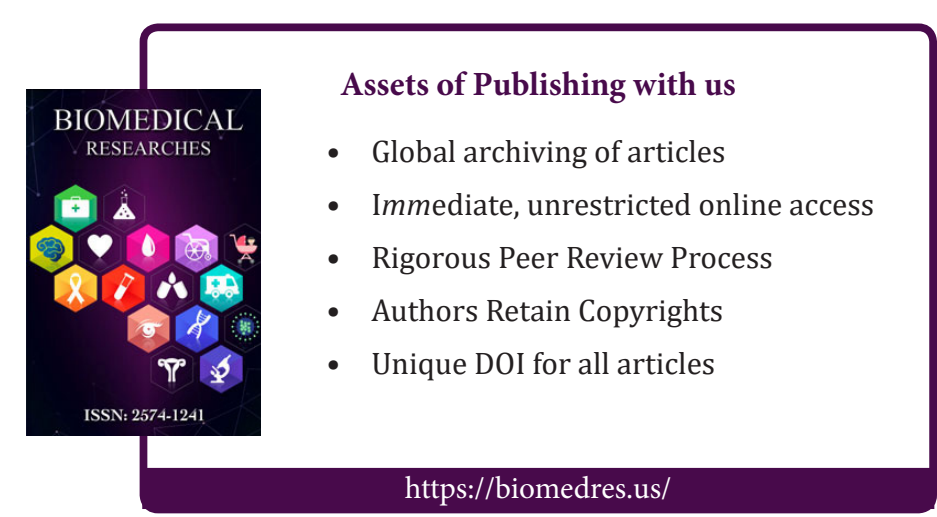

